\title{
KẾT QUẢ PHẪU THUÂTT XÂM LẤN TỐI THIỂU HÀN XƯƠ'NG LIÊN THÂN ĐốT QUA LỖ LIÊN HỢP ĐIỀU TRI TRƯợT ĐỐT SỐNG THẮT LƯNG
}

TÓM TẮT.

Mục tiêu nghiên cứu: Mô tả đăc điểm lâm sàng và hình ảnh hoc trượt đốt sống thắt lưng của bệnh nhân được phẫu thuật xâm lấn tối thiểu hàn xươnng liên thân đốt qua lỗ liển hợp và đánh giá kết quả phẫu thuật xâm lấn tối thiểu hàn xương liên thân đốt qua lố liên hợp điều trị trượt đốt sống thắt lưng. Đối tướng và phương pháp nghiên cứu: Nghiên cứu mố tả cắt ngang, hồi cứu, tiến cứu 41 bênh nhân được chẩn đoán xác định trượt đốt sống thắt lưng có chỉ định can thiêp phẫu thuât xâm lấn tối thiểu hàn xương liên thân đốt qua lỗ liên hợp tại khoa Phẫu thuật cột sốngBênh viên Hưu nghi Việt Đức. Kết quả: Tuổi trung

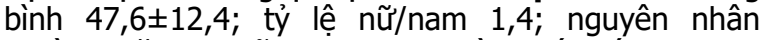
thường găp do gãy eo $29,3 \%$ và thoái hóa $63,4 \%$; tânng trượt hay gặp nhất L4 53,7\%, L5 34,1\%; các triệu chứng bao gồm đau lưng $100 \%$, đau rễ thần kinh $78 \%$, rối loạn cảm giác $51,2 \%$, đau cách hồi thần kinh 65,9\%; VAS lưng, chân trước phẫu thuật $6,4 \pm 0,9,5,4 \pm 2,3$; ODI trước phẫu thuật $24 \pm 8,1 \%$; tăng \% trượt X-quang động so với X-quang thường $3,9 \pm 2,5 \%(p<0,01)$; thời gian phấu thuật trung bình $140 \pm 35$ phút; lượng máu mất trung bình $270 \pm 110 \mathrm{ml}$; không biến chứng; thời gian nằm viện trung bình $6 \pm 2,1$ ngày; thời gian đi lại sau mổ trung bình $2,4 \pm 0,7$ ngày; có sự khác biểt giữa VAS lưng, chân trước phẫu thuật sơ với khi ra viện $(p<0,001)$; giảm độ trượt trước phẫu thuật so với ra viện $(p<0,001)$; $100 \%$ vít và miếng ghép đúng vị trí; chiều cao LTÐ trước phẫu thuật $2,9 \pm 0,15 \mathrm{~mm}$, sau phẫu thuật $5 \pm 1 \mathrm{~mm}(p<0,001)$, kết quả sau 18 tháng theo Macnab: Rất tốt 12,2\%; tốt 74,4\%; khá 7,4\%. Kết luận: Trượt đốt sống thắt lưng là một bệnh thường găp ở đô tuổi trung niên do hai nguyên nhân chính là gã̃y eo và thoái hóa, các triệu chứng chính là đãu lưng, đau rễ thần kinh, rối loạn cảm giác, việc phẫu thuật xâm lấn tối thiểu giúp giảm lượng máu mất, rút ngắn thời gian nằm viện, giảm biến chứng, phục hồi sớm cho người bệnh.

Tư khóa: đau lưng, trượt đốt sống thắt lưng, thang điểm VAS, thang điểm ODI.

\section{SUMMARY}

RESULTS OF MINIMALLY INVASIVE SURGERY TRANSFOMIRANAL LUMBAR INTERBODY FUSION TO TREATMENT LUMBAR SPONDYLOLISTHESIS

Objective: The aims of the study is to describe 1 Trường Đại học Y Dước Thái Nguyên
2Bệnh viện Hữu Nghi Việt Đức

Chịu trách nhiệm chính: Dương Tùng Anh

Email: tungmu31071994@gmail.com

Ngày nhận bài: 5.4.2021

Ngày phản biên khoa hoc: 26.5.2021

Ngày duyệt bài: 7.6.2021

\section{Dương Tùng Anh ${ }^{1}$, Nguyễn Hoàng Long ${ }^{2}$}

the characteristics of clinical, imaging and evaluate results of minimally invasive surgery transfomiranla lumbar interbody fusion to treatment lumbar spondylolisthesis. Study method: Across- sectional descriptive, retrospective, prospective method was carried out on 41 patients was diagnosed with benign lumbar spondylolisthesis who was indicated to minimally invasive surgery transfomiranal lumbar interbody fusion in Spine Surgery Department in Viet

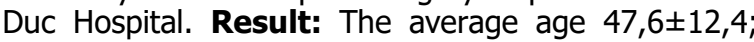
ratio female/male 1,4; common cause is par defect $29,3 \%$ and degenerative $63,4 \%$; most common level is L4 $56 \%$, L5 36,6\%; patients had symptom include back pain $100 \%$, radicupathy $78 \%$, paraesthesia $51,2 \%$, neurologic claudication $65,9 \%$; preoperative VAS back, leg is $6,4 \pm 0,9$ and $5,4 \pm 2,3$; ODI $24 \pm 8,1 \%$, percent of spondylolisthesis increase on dynamic X-ray imaging was $3,9 \pm 2,5 \% \quad(p<0,001)$; the average surgery time $140 \pm 35 \mathrm{mins}$; the average blood loss $270 \pm 110 \mathrm{ml}$; no complication; the average time in hospital stay $6 \pm 2$,1days; the postoperative average

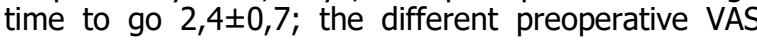
and spondylolisthesis grade versus postoperative has statistical significance $(p<0,001) ; 100 \%$ screws and graphs positions was right; preoperative interbody height versus postoperative was $2,9 \pm 0,15 \mathrm{~mm}$, $5 \pm 1 \mathrm{~mm}$ and the different has statistical significance $(p<0,001), 18$ months postoperativefollow-up of Macnab: Very good 12,2\%; Good 74,4\%; Fair 7,4\%. Conclusion: Lumbar spondylolisthesis disease is common in middle-age, cause by par defect and degenerative, symptom include back pain, radicupathy, paraesthesia, patients who underwent minimally invasive surgery was decreased blood loss, time in hospital, complication and come back daily life soon.

Keyword: back pain, lumbar spondylolisthesis, VAS, ODI questionaire

\section{I. ĐĂT VẤN ĐỀ}

Trượt đốt sống (TĐS) là sự di chuyển bất thường ra phía trước của thân đốt sống cùng với cuống, mỏm ngang và diện khớp phía trên [1]. Cơ chế của bênh khá phức tạp và còn nhiều tranh cãi, tuy nhiên nguyên nhân được chấp thuâan nhiều nhất là do những vi chấn thương lặp đi lặp lại. Bệnh thường gặp nhất ở lứa tuổi thanh thiểu niên, vị trí hay gặp nhất là đoạn thấp của lưng, $L 5$ khoảng $95 \%$ và giảm dần lền cao, theo Alan G.Shamrock và cộng sự 2019, tỷ lệ này là 90\% đoan L5-S1.

Mục tiêu điêu trị là giảm đau và cải thiện chất lượng cuộc sống cho bệnh nhân, điều trị nội khoa khi bênh nhân chưa có biểu hiện về chèn ép thần kinh. Chỉ định phẫu thuật trong trường hợp điều trị nội khoa không kết quả, bệnh nhân 
đau lưng man tính, độ trượt tiến triển, hoăc trong trường hợp bệnh nhân có biểu hiện chèn ép thần kinh.

Hiên nay, tai các trung tâm phẫu thuât thần kinh chuyên khoa đã tiến hành phẫu thuật thường quy kĩ thuật cố định cột sống thắt lưng bằng nẹp vis qua cuống và hàn xương liên thân đốt qua lỗ liên hợp (TLIF) đem lại kết quả khả quan. Theo Nicandro 2004 nghiên cứu trên 24 bệnh nhân được phẫu thuật bằng phương pháp TLIF cho kết quả rất tốt $83,3 \%$ bênh nhân cải thiên triêu chứng đau. Theo Kunder 2017 so sánh giữa TLIF và PLIF cho thấy giảm lượng máu mất trong mổ $418 \mathrm{ml}$ so với $350 \mathrm{ml}$, giảm tỷ lệ biến chứng rách màng cứng[7], tuy nhiên kĩ thuật phẫu thuật xâm lấn tối thiểu hàn xương liên thân đốt qua lỗ liên hợp (MIS-TLIF) cho kết quả tốt hơn, nhiều nghiên cứu trên thế giới đã cho thấy MIS- TLIF giảm lượng máu mất trong phẫu thuật, giảm đau sau phẫu thuật tốt hơn, ít tổn thương mô mềm, rút ngắn thời gian nắm viện, giảm tỷ lệ biến chứng sau phẫu thuật[6], Mặc dù vậy, cho đến nay tại Việt Nam vẫn còn ít nghiên cứu về kĩ thuật cũng như hiệu quả điều trị của phương pháp phẫu thuật này. Chính vì vậy, nghiên cứu này được thực hiện với mục tiêu: Mô tả đặc điểm lâm sàng, hình ảnh học trướt đốt sống thắt lưng và đánh giá kết quả phẫu thuât xâm lấn tối thiểu hàn xương liên thân đốt qua lỗ liên hợp điều trị trượt đốt sống thắt lưng.

II. ĐỐI TƯỢNG VÀ PHƯƠNG PHÁP NGHIÊN CỨU

2.1. Đối tương nghiên cứu. Bênh nhân chẩn đoán xác đinh trượt đốt sống thắt lưng, được chỉ định phẩu thuật xâm lấn tối thiểu hàn xưởng liên thân đốt qua lố liên hợp tại Khoa Phẫu thuật cột sống- Bệnh viện Hữu Nghị Việt Đức từ tháng 01/2019 đến 06/2021, thỏa mãn tiêu chuẩn nghiên cứu.

\subsubsection{Tiêu chuẩn lựa chọn bệnh nhân}

- Bênh nhân được chẩn đoán xác đinh trượt đốt sống thắt lưng qua khám lâm sàng và cận lâm sàng như X-quang qui ước, X-quang động, MRI, CLVT cột sống thắt lưng.

- Bênh nhân có triêu chứng thần kinh cấp hoăc triệu chứng thần kinh tăng dần mà điều trị nội khoa dài ngày không đõ.

\subsubsection{Tiêu chuẩn loạn trừ}

- Bênh nhân từ chối tham gia nghiên cứu.

- Trượt đốt sống đô 3, 4.

- Trượt đốt sống không có triệu chứng.

- Đã phẫu thuật ghép xương sau bên trước đó.

2.2. Thời gian và địa điểm nghiên cứu. Từ 01/2019 - 06/2021 tại khoa Phẩu thuật cột sống - Bênh viên Hữu nghi Viêtt Đức.

2.3. Phương pháp nghiên cứu

Phương pháp nghiên cứu: Mô tả

Thiết kếnghiên cứu: Cắt ngang

Cỡ mẫu: Dưa công thức tính cỡ mẫu cho nghiên cứu mô tả: Chọn $\mathrm{p}=0.919$ (tỷ lệ bệnh nhân có kết quả tốt sau mổ của nghiến cứu trước khoảng 91,9\%); d: sai số cho phép (độ chính xác tuyêt đối) $=0,0919$. Tính được $n=34$, thực tế lấy 41 bệnh nhân đủ tiêu chuẩn.

Chon mẫu: Có chủ đích

2.4. Chỉ số nghiên cứu và tiêu chuẩn đánh giá

- Đánh giá mức độ đau theo thang điểm VAS.

- Đánh giá mức hạn chế chức năng cột sống theo thang điểm ODI.

- Đánh giá kết quả chung theo tiêu chuẩn Macnab.

2.5. Xử lý số liệu. Số liệu nghiên cứu được xử lý theo các thuật toán thống kê bằng phẩn mềm SPSS 18.0.

\section{KẾT QUẢ NGHIÊN CỨU}

Qua nghiên cứu 41 bệnh nhân trượt đốt sống thắt lưng có chỉ đinh phẫu thuâat tại khoa Phẫu thuật cột sống- Bềnh viện Hữu nghị Việt Đức, thu được kết quả như sau:

\section{Bảng 1: Phân bố bênh theo nhóm tuổi}

\begin{tabular}{|c|c|c|c|}
\hline $\begin{array}{c}\text { Nhóm } \\
\text { tuổi }\end{array}$ & $\begin{array}{c}\text { Số lượng } \\
\text { (n) }\end{array}$ & $\begin{array}{l}\text { Tỷ lêe } \\
(\%)\end{array}$ & $\begin{array}{l}X \pm \\
\text { SD }\end{array}$ \\
\hline $18-29$ & 2 & 4,9 & \multirow{4}{*}{$\begin{array}{c}47,6 \pm 1 \\
2,4\end{array}$} \\
\hline $30-49$ & 21 & 51,2 & \\
\hline $50-69$ & 17 & 41,5 & \\
\hline$\geq 70$ & 1 & 2,4 & \\
\hline
\end{tabular}

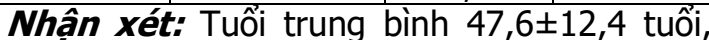
trong đó nhóm tuổi có tỷ lê cao nhất từ 30-49 tuổi 51,2\%, tiếp đó là 50-69 tuổi 41,5\%.

Bảng 2: Tỷ lệ bênh theo giới

\begin{tabular}{|c|c|c|}
\hline Giới & Số lượng & Tỷ lệ(\%) \\
\hline Nam & 17 & 41,5 \\
\hline Nữ & 24 & 58,5 \\
\hline
\end{tabular}

Nhân xét: Bệnh gặp ở nữ nhiều hơn nam, tỷ lệ nữ/nam là 1,4 .

Bảng 3. Nguyên nhân trượt đốt sống thắt lưng

\begin{tabular}{|c|c|c|}
\hline Nguyên nhân & Số lượng (n) & Tỷ lệ (\%) \\
\hline Thoái hóa & 26 & 63,4 \\
\hline Khuyết eo & 12 & 29,3 \\
\hline Vi chấn thương & 3 & 7,3 \\
\hline Tống & $\mathbf{4 1}$ & $\mathbf{1 0 0}$ \\
\hline
\end{tabular}

Nhân xét: Nguyên nhân gây trượt đốt sống do thoái hóa chiếm tỷ lệ cao nhất $63,4 \%$, tiếp đó do khuyết eo chiếm tỷ lệ 29,3\% và thấp nhất do vi chấn thương chiếm tỷ lê $7,3 \%$.

Bảng 4. Vị trí trượt đốt sông thắt lưng 


\begin{tabular}{|c|c|c|}
\hline Vị trí & Số lượng (n) & Tỷ lệ (\%) \\
\hline L1 & 0 & 0 \\
\hline L2 & 1 & 2,5 \\
\hline L3 & 2 & 4,9 \\
\hline L4 & 23 & 56 \\
\hline L5 & 15 & 36,6 \\
\hline
\end{tabular}

Nhân xét: Vị trí trượt đốt sống thắt lưng hay găp nhất là $L 4$ chiếm tỷ lệ $56 \%$, tiếp đó là $L 5$ chiếm tỷ lệ $36,6 \%$, thấp nhất là tânng L2 L3 chiếm tỷ lệ 2,5\% và 4,9\%.

Bảng 5. Triệu chứng cơ năng trước phẫu thuât

\begin{tabular}{|c|c|c|}
\hline $\begin{array}{c}\text { Các triệu chứng cơ } \\
\text { năng }\end{array}$ & $\begin{array}{c}\text { Số lượng } \\
\text { (n) }\end{array}$ & $\begin{array}{c}\text { Tỷ lệ } \\
\text { (\%) }\end{array}$ \\
\hline $\begin{array}{c}\text { Đau lưng đơn thuânn } \\
\text { Đau lưng có chèn ép rễ } \\
\text { thần kinh } \\
\text { 1 bên }\end{array}$ & 9 & 22 \\
2 bên & 16 & 39 \\
\hline $\begin{array}{c}\text { Đau cách hồi thân kinh } \\
\text { < 100m }\end{array}$ & 16 & 39 \\
100 - 500m & 10 & 24,4 \\
> 500m & 10 & 24,4 \\
\end{tabular}

Nhânn xét: Triệu chứng cơ năng trước phẫu thuật bao gôm đau lưng có hoặc không đau rễ thần kinh 1 bên hay 2 bên và đau cách hồi thân kinh.

Bảng 8. Mức độ đau trước phẫu thuật theo thang điểm VAS

\begin{tabular}{|c|c|c|c|c|}
\hline & $\begin{array}{l}\text { Số lượng } \\
\text { (n) }\end{array}$ & $\begin{array}{l}\text { Tỷ lệ } \\
(\%)\end{array}$ & $\overline{\boldsymbol{X}}$ & SD \\
\hline \multicolumn{5}{|c|}{ VAS lưng } \\
\hline $\begin{array}{l}3-4 \\
5-6 \\
7-8\end{array}$ & $\begin{array}{l}22 \\
19\end{array}$ & $\begin{array}{l}53,7 \\
46,3\end{array}$ & 6,4 & 0,9 \\
\hline \multicolumn{5}{|c|}{ VAS chân } \\
\hline $\begin{array}{c}0 \\
1-2 \\
3-4 \\
5-6 \\
7-8\end{array}$ & $\begin{array}{c}3 \\
3 \\
2 \\
18 \\
15\end{array}$ & $\begin{array}{c}7,3 \\
7,3 \\
4,8 \\
43,9 \\
36,7\end{array}$ & 5,4 & 2,2 \\
\hline
\end{tabular}

Nhân xét: Mức đô đau lưng và đau chân của bênh nhân trước phẫu thuật nằm nhiều nhất trong khoảng VAS 5-6 điểm và 7-8 điểm.

Bảng 9. Triêuu chứng thưc thể của trươt đốt sống trước phẫu thuật

\begin{tabular}{|c|c|c|}
\hline Triệu chứng thực thể & $\begin{array}{c}\text { Số lượng } \\
\text { (n) }\end{array}$ & $\begin{array}{c}\text { Tỷ lệ } \\
\text { (\%) }\end{array}$ \\
\hline Dấu bậc thang & 8 & 19,5 \\
\hline Co cứng cơ cạnh sống & 40 & 97,6 \\
\hline Giảm phản xạ gân & & \\
xương chi dưới & 1 & 2,4 \\
Tăng phản xạ gân & 2 & 4,9 \\
xương chi dưới & & \\
\hline Rối loạn cảm giác & & \\
\hline
\end{tabular}

\begin{tabular}{|c|c|c|}
\hline Tê, dị cảm & 18 & 43,9 \\
Tê + giảm cảm giác & 3 & 7,3 \\
Không rối loạn & 20 & \\
\hline Rối loạn vận động & & \\
Sức cơ 2/5 & 0 & \\
Sức cơ 3/5 & 1 & \\
Sức cơ 4/5 & 0 & 2,4 \\
Sức cơ 5/5 & 40 & \\
\hline
\end{tabular}

Nhận xét: Triệu chứng thực thế của bệnh nhân trước phẫu thuật thường gặp nhất là co cứng cơ canh sống chiếm ty lệ $97,6 \%$, dị cảm 43,9\%, dấu hiệu bậc thang 19,5\%, một số ít trường hợp có rối loạn vận động và phản xạ gân xương.

Báng 10. Mức độ giảm chức năng cột sống ODI trước phẫu thuật

\begin{tabular}{|c|c|c|c|c|}
\hline & $\begin{array}{c}\text { Số lượng } \\
\text { (n) }\end{array}$ & $\begin{array}{c}\text { Tỹ lệ } \\
(\%)\end{array}$ & $\begin{array}{c}\overline{\boldsymbol{X}} \\
(\mathbf{\%})\end{array}$ & $\begin{array}{c}\text { SD } \\
(\mathbf{\%})\end{array}$ \\
\hline ODI & 11 & 26,8 & & \\
Mức 1 & 28 & 68,3 & & \\
Mức 2 & 2 & 4,9 & 24 & 8,1 \\
Mức 3 & 0 & 0 & & \\
Mức 4 & 0 & 0 & & \\
Mức 5 & 0 &
\end{tabular}

Nhận xét: Mức độ giảm chức năng cột sống ODI trước phẫu thuât ở mức độ 2 chiếm tỷ lế cao nhất $68,3 \%$, tiếp đó mức $126,8 \%$ và thấp nhất là mức 3 với tỷ lệ 4,9\%.

Bảng 11. Đăc điếm hình ảnh trướt đôt sống trên Xquang oộng và so sánh với $X$ quang qui ước

\begin{tabular}{|c|c|c|c|c|}
\hline Đặc điểm & $\begin{array}{c}\text { Số lướng } \\
\text { (n) }\end{array}$ & $\begin{array}{c}\text { Tỷ lệ } \\
(\%)\end{array}$ & $\overline{\bar{X}} \mathbf{( \% )}$ & $\mathbf{p}$ \\
\hline $\begin{array}{c}\text { Mức độ TĐS } \\
\text { Độ 1 } \\
\text { Độ 2 }\end{array}$ & $\begin{array}{c}35 \\
6\end{array}$ & $\begin{array}{c}85,4 \\
14,6\end{array}$ & & \\
\hline $\begin{array}{c}\text { Tăng \% độ } \\
\text { trượt: Có } \\
\text { Không }\end{array}$ & 41 & 100 & $\begin{array}{c}3,9 \\
\pm 2,5\end{array}$ & $\begin{array}{c}\text { p } \\
0,01\end{array}$ \\
\hline
\end{tabular}

Nhận xét: Trên X-quang động trượt độ I

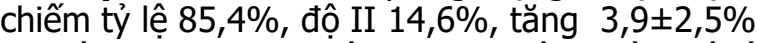
so với xquang qui ước, sự so sánh này có ý nghĩa thống kê với $p<0,01$.

Báng 12. Thởi gian mổ và lượng máu mất trong phẫu thuật

\begin{tabular}{|c|c|}
\hline & $\boldsymbol{X} \pm$ SD \\
\hline Thời gian mố (phút) & $140 \pm 35$ \\
\hline Lượng máu mất (ml) & $270 \pm 110$ \\
\hline Lượng máu phải truyền (ml) & 0 \\
\hline
\end{tabular}

Nhận xét: Thời gian phâu thuật trung bình là $140 \pm 35$ phút, lượng máu mất trung bình là $270 \pm 110 \mathrm{ml}$, không có bệnh nhân nào phải truyên máu.

Bảng 13. So sánh điểm VAS trước và lúc ra viện

\begin{tabular}{|c|c|c|c|}
\hline & \multicolumn{2}{|c|}{$\overline{\boldsymbol{x}} \pm \mathbf{S D}$} & P \\
\hline VAS & Trước phâu & Lúc ra & \\
\hline
\end{tabular}




\begin{tabular}{|c|c|c|c|}
\hline & thuật & viện & \\
\hline Lưng & $6,4 \pm 0,9$ & $2,1 \pm 0,6$ & 0,000 \\
\hline Chân & $5,4 \pm 2,3$ & $2,1 \pm 0,6$ & 0,000 \\
\hline
\end{tabular}

Nhân xét: Mức độ đau lưng và chân tính theo thang điểm VAS trước phẫu thuât và lúc ra viện có sự khác biệt, sự khác biệt này có ý nghĩa thống kê với $p<0,001$.

Bảng 14. Đánh giá mức độ nắn chỉnh trượt sau mố

\begin{tabular}{|c|c|c|c|c|c|}
\hline \multicolumn{2}{|c|}{ (1) } & \multicolumn{2}{|c|}{$\begin{array}{l}\text { Độ trượt } \\
\text { trước mổ }\end{array}$} & \multirow[t]{2}{*}{ Tổng } & $\mathbf{p}$ \\
\hline Độ & & Độ 1 & Độ 2 & & \multirow{4}{*}{$p<0,001$} \\
\hline trượt & Độ 0 & 34 & 1 & 35 & \\
\hline sau mổ & Dộ 1 & 1 & 5 & 6 & \\
\hline Tống & & 35 & 6 & 41 & \\
\hline
\end{tabular}

Nhân xét: Độ trượt sau phầu thuật giảm so với trước phẫu thuật, có sự khác biệt giữa độ trướt trước phẫu thuâat và sau phẫu thuật. Sự khác biệt này có ý nghĩ̃a thống kê với $p<0,001$.

Bảng 15. So sánh chiều cao liên thân đốt trước và sau mổ lúc ra viện

\begin{tabular}{|l|c|c|c|}
\hline & \multicolumn{2}{|c|}{$\overline{\boldsymbol{X}} \pm$ SD } & p \\
\hline & $\begin{array}{c}\text { Trước } \\
\text { mổ }\end{array}$ & $\begin{array}{c}\text { Lúc ra } \\
\text { viện }\end{array}$ & \\
\hline $\begin{array}{c}\text { Chiều cao } \\
\text { LTפ (mm) }\end{array}$ & $2,9 \pm 0,15$ & $5 \pm 1$ & $\mathrm{P}<0.001$ \\
\hline
\end{tabular}

Nhânn xét: Chiều cao liên thân đốt sau phẫu thuất tăng so với trước phẫu thuât, có sư khác biêt giữa chiều cao liên thân đốt trước và sau phẫu thuật, sự khác biệt này có ý nghĩa thống kê với $p<0,001$.

Bảng 16. Kêt quả điều trị sau phẫu thuật 18 tháng theo MacNab

\begin{tabular}{|c|c|c|}
\hline MacNab & Số lượng (n=27) & Tỷ lệ (\%) \\
\hline Rất tốt & 5 & 12,2 \\
Tốt & 20 & 74,1 \\
Khá & 2 & 7,4 \\
Xấu & 0 & 0 \\
\hline
\end{tabular}

Nhân xét: Kết quả điều trị sau phầu thuật 18 tháng theo Macnab cho kết quả rất tốt $12,2 \%$; kết quả tốt 74,1\%, khá 7,4\%

\section{BÀN LUẬN}

Đặc điểm lâm sàng trượt đốt sống thắt lưng

Triệu chứng cơ năng. Đau lưng mãn tính, đau theo rễ và đau cách hồi thần kinh là những triệu chứng cơ năng rất thường gặp trong TĐS thắt lưng. Trong nghiên cứu của chúng tôi nhận thây rằng tất cả các $\mathrm{BN}$ TĐS đều có triệu chứng đau thắt lưng, trong đó $39 \%$ đau thắt lưng kèm theo đau rễ 1 bên và $39 \%$ đau thắt lưng kèm đau rễ 2 bên, có $22 \%$ chỉ có đau thắt lưng không đau theo rễ.

Theo Denark 2010 nghiên cứu trên 92 bênh nhân trượt đốt sống thắt lưng, tỷ lệ bệnh nhân có đau lưng là $63 \%$, biểu hiện chèn ép thần kinh $33 \%$, dị cảm $18 \%$, yếu cớ $18 \%$. Theo Nayak 2015 nghiên cứu trên 56 bệnh nhân trượt đốt sống thắt lưng, $100 \%$ bệnh nhân có đau lưng, trong đó $42,9 \%$ đau lưng lan xuống 2 chân, $35,7 \%$ đau lưng lan xuống 1 bên chân trái, $21,4 \%$ đau lưng lan xuống 1 bên chân phải.

Trong nghiên cứu của chúng tôi, mức độ đau được đánh giá theo thang điểm VAS. Điểm đau trung bình ở lưng là $6,4 \pm 0,9$, ở chân là $5,4 \pm$ 2,2. Kết quả này cũng tương đồng với kết quả của các tác giả khác như Nguyễn Vũ, điểm VAS lưng trung bình là $6,62 \pm 1,35$, VAS chân trung bình là $6,02 \pm 1,53$. Võ Văn Thanh ghi nhận điểm VAS lưng trung bình là $5,6 \pm 1,6$, VAS chẩn là $5,3 \pm 2,3$. Phạm Vô Ky điểm đau trung bình ở lưng là $6,98 \pm 0,78$, ở chân là $7,24 \pm 1,07$.

Nghiên cứu của chúng tôi cũng ghi nhận có $24,4 \%$ đau cách hồi thần kinh với khoảng cách $100-500 \mathrm{~m}$ và $24 \%$ đau cách hồi thần kinh $<100 \mathrm{~m}$. Đây là triệu chứng được cho là do hẹp ống sống gây nên, thường gặp trong TĐS do thoái hóa.

Nghiên cứu Võ Văn Thanh cũng cho thấy tỷ lệ BN đau cách hồi khá cao, chiếm $67,6 \%$ với đau cách hồi dưới $100 \mathrm{~m}$. Phan Trọng Hậu ghi nhận tỷ lệ này là 63\%. Nghiên cứu Phạm Vô Ky. 38,7\% đau cách hồi thần kinh với khoảng cách 100$500 \mathrm{~m}$ và $3,2 \%$ đau cách hồi thần kinh $<100 \mathrm{~m}$.

Triệu chứng thực thể. Triệu chứng trượt đốt sống thường khổng đặc hiệu dễ nhầm với một số bệnh lý khác như thoát vị đĩa đệm, thoái hóa cột sống, bệnh lý khớp cùng chậu, bệnh lý thần kinh cơ

Dâu hiệu bậc thang mặc dù là dấu hiệu đặc trưng của trượt đốt sống tuy nhiên không dề để phát hiện đặc biệt trong trường hợp độ trượt thấp, bệnh nhân béo phì, trong nghiên cứu này chúng tồi phát hiện 8 trường hợp $(19,5 \%)$ bệnh nhân có dấu hiệu bậc thang. Nghiên cứu Phạm Vô Ky 27,4\% bệnh nhân có dấu hiệu bậc thang, Nguyễn Vũ phát hiện có $23,3 \%$ BN có dấu hiệu bậc thang. Một nghiên cứu khác của Võ Vằn Thanh thấy có $35,3 \% \mathrm{BN}$ có dấu hiệu này. Phan Trọng Hậu cũng nhận thây dấu hiệu này lại khá thấp khoảng 7\% trong bệnh lý TĐS.

Rối loạn cảm giác, dị cảm ở da kiểu tê bì trong nghiên cứu này chúng tôi gặp $51,2 \%$, nghiên cứu Phạm Vô Ky. 79\%, Võ Văn Thanh nhận thấy rối loạn cảm giác ở $61,8 \%$ BN, chủ yếu là dị cảm da. Theo Denark 2010 nghiên cứu trên 92 bệnh nhân trượt đốt sống thắt lưng trong đó bểnh nhân có biểu hiện di cảm $18 \%$.

\section{Đặc điểm hình ảnh học}


Xquang qui ước. Phân loại độ trượt theo Mayerding trên Xquang qui ước tư thế nghiêng. Chúng tôi phát hiện TĐS độ I 85,4\%, độ II $14,6 \%$. Kết quả này tương đồng với các tác giả khác như: Phạm Vô Ky TĐS độ I chiếm đa số với $79 \%$ và $21 \%$ trượt độ II, Phan Trọng Hậu trượt độ I là $51,4 \%$, độ II là $41,4 \%$. Nghiên cứu của Võ Văn Thanh cũng có kêt quả tương tự, TĐS độ I chiếm 63,2\%, trượt độ II là 30,9\%.

Khuyết eo phát hiện 36,6\% trường hợp. Phạm Vô Ky phát hiện 27,7\% trường hợp khuyết eo trên X-quang qui ước.

Xquang động. $100 \%$ bệnh nhân tăng phần trăm trượt trên Xquang động so với Xquang qui ước, với 2 tứ thế cúi và ưỡn tối đa giúp phát hiện chính xác độ trượt, gãy eo mà đôi khi Xquang qui ước còn bỏ sót.

Cộng hượng từ. Trong nghiên cứu này chúng tôi phát hiện $48,8 \%$ bệnh nhân có gãy eo, $75,6 \%$ bệnh nhân có thoát vị đĩa đệm, $92,7 \%$ bệnh nhẩn có hẹp lố liên hợp trong đó $90,2 \%$ bệnh nhân có chèn ép rễ trong lỗ liên hợp, phì đại mấu khớp 85,4\%.

Phân độ thoái hóa đĩa theo Pfirrman tại tầng trượt chủ yếu là độ III $70,7 \%$ đó là hình ảnh đĩa đệm mất nước giảm tín hiệu trên $T 2$, không còn phân biệt được giữa vòng xơ và nhân nhầy, chiều cao liên đốt giảm nhẹ đến trung bình, dưới tầng trượt độ I 34,1\%, trên tầng trượt độ I 75,6\%.

Kết quả phẩu thuất. Thời gian phẫu thuật trung bình $140 \pm 35$ phút, lượng máu mất trung bình $270 \pm 110 \mathrm{ml}$, không có trường hợp nào phải truyền máu. Nghiên cứu của Lê Ngọc Quang lượng máu mất trung bình là $114,52 \mathrm{ml}$. Nghiên cứu của Arikat $A$. và $C S$, thời gian mổ trung bình 170 phút, lượng máu mất $148 \mathrm{ml}$. Theo Phạm Vô Ky. thời gian mổ trung bình 157,34 phút, lượng máu mất trung bình $158,55 \mathrm{ml}$. Theo Lee $\mathrm{H} . \mathrm{J}$ và CS (2016), thời gian mổ là 182 phút, lượng máu mất $249 \mathrm{ml}$. Một nghiên cứu khác của Tender G.C. và CS có thời gian mổ 189 phút, lượng máu mất là $170 \mathrm{ml}$. Theo Millimaggi D.F. và CS (2017), cũng cho kết quả tương đồng với các tác giả trên, rất ít mất máu trong mổ với $170 \mathrm{ml}$ và thời gian phẫu thuật trung bình là 230 phút. Điều này chứng tỏ ưu điểm của phẫu thuật ít gây tổn thương mô mềm, hạn chế lượng máu mất.

Mức độ đau của bệnh nhân được cải thiện so với trước mổ từ VAS lưng 6,4 xuống 2,1 , VAS chân 5,4 xuống $2,1 \quad(p<0,001)$, thời gian nằm viện trung bình $6 \pm 2,1$ ngày, đi lại sau mổ trung bình $2,4 \pm 0,7$ ngày, không có trường hợp nào phát hiện biến chứng. Điêuu đó chứng tỏ hiệu quả của phương pháp phẫu thuật rút ngắn thời gian nằm viện, giảm đau sau mổ hiệu quả, khả năng ngồi dậy, phục hồi đi lại được rút ngắn, từ đó giúp bệnh nhân tiết kiệm được kinh tế đồng thời trở lại sớm hơn với hoạt động và công việc thường ngày.

\section{KẾT LUẦN}

Trượt đốt sống thắt lưng biểu hiện lâm sàng chủ yếu bởi các triệu chứng đau lưng, đau rể thần kinh, rối loạn cảm giác, bệnh dễ chẩn đoán nhầm với các bệnh lý khác như thoát vị đĩa đệm, thoái hóa cột sổng, bệnh lý khớp cùng chậu, việc chẩn đoán xác định dựa vào chụp X-quang, cộng hưởng từ, trong đó $X$-quang động có giá trị hơn so vỡi $X$-quang qui ước, việc chụp cộng hưởng từ đánh giá tình trang đĩa đệm, iố liển hợp, phát hiện chèn ép rễ thần kinh trong lỗ liên hợp. Phương pháp phẫu thuật xâm lấn tối thiểu hàn xương liên thân đốt qua lỗ liên hợp điều trị trượt đốt sống thắt lưng ít làm tổn thương mô mềm, hạn chế lượng máu mất, rút ngắn thời gian nằm viện, phục hồi sớm, tiết kiệm kinh tế, sớm quay lại với cồng việc và hoât động thường ngày so với các phương pháp phẫu thuật trước đó.

\section{TÀI LIỆ THAM KHẢO}

1. Nguyễn Vũ (2015). "Nghiên cứu điều trị trượt đốt sống thắt lưng bằng phương pháp cố định cột sống qua cuống kết hợp hàn xương liên thẩn đốt"i. Luận án Tiến sĩ Y học.

2. Phạm Vô Ky (2018). "Nghiên cứu ứng dụng phẫu thuật xâm lẩn tối thiểu điểu trị trượt đốt sống thắt lưng một tầng". Luận án Tiến sĩ Y học.

3. Lê Ngọc Quang (2013). Nghiên cứu kết quả phẫu thuật bắt vit chân cung tối thiểu có sử dụng ống banh CASPAR điêu trị trượt đốt sống thắt lứng một tầng. Luân án chuyên khoa II, Học viện Quân y.

4. Nguyển Hù̀ng Minh, Nguyễn Xuân Phương (2010). Đánh giá lâm sàng, kết quả điêuu trị trượt đốt sống thắt lưng bệnh lỳ bằng phẩu thuật nẹp vis qua cuống sống tạ̣i bệnh viện 103. Y học thực hành, 716:82-86.

5.Phan Trọng Hâu (2006). Nghiên cứu chẩn đoán và điều trị phẩu thuât bênh trượt đốt sống thắt lưng do hở eo ở người trửơng thành. Luận án tiến sĩ Y học, Học viện Quân y.

6. Transforaminal Lumbar Interbody Fusion for the Treatment of Single-Level Spondylolisthesis Grades 1 and 2: A Systematic Review and MetaAnalysis". World Neurosurg, 122 180-189.

7.Kunder S, Rijkers K, Caelers I, et al (2017). "Lumbar Interbody Fusion, A Historical Overview and A Future Perspective".' SPINE, 431.

8. Denard $P$ J, Holton K F, Miller J, et al (2010). "Back pain, neurogenic symptoms, and physical function in relation to spondylolisthesis among elderly men". The Spine Journal, 10 (10), 865-873.

9. Vazan M, Gempt J, Meyer B, et al (2017). "Minimally invasive transforaminal lumbar interbody fusion versus open transforaminal lumbar interbody fusion: a technical description and review of the literature". Acta Neurochirurgica, 159 